\title{
Meningkatkan Pola Pengasuhan Otoritatif melalui Program Excellent Parenting
}

\author{
Improving Authoritative Parenting through the Excellent Parenting Program
}

\author{
Rifa Hidayah \\ Fakultas Psikologi, Universitas Islam Negeri Maulana Malik Ibrahim, Malang, Indonesia
}

\begin{abstract}
Successful motherhood in educating children requires learning how to best care for children. Excellent parenting programs make it easier for mothers to better care for their children. The study aim was to examine the effect of "excellent parenting program" on the authoritative parenting patterns of mothers. A total number of 14 mothers were involved in this study. A quasi-experimental method was used. Data was collected using the authoritative parenting scale, and analyzed using t-test. The result shows that the excellent parenting program has a positive effect on the improvement of mother's authoritative parenting. This study concludes that the excellent parenting program provides benefits for mothers to improve their authoritative parenting skills.
\end{abstract}

Key words: Authoritative parenting, excellent parenting program, mother

\begin{abstract}
Abstrak: Sukses menjadi ibu dalam mendidik anak memerlukan belajar bagaimana mengasuh yang terbaik untuk anak. Program excellent parenting membantu memudahkan ibu dalam menerapkan pola pengasuhan anak secara otoritatif. Tujuan penelitian adalah menguji pengaruh program excellent parenting terhadap pola pengasuhan otoritatif ibu. Metode penelitian yang digunakan adalah kuasi-eksperimen terhadap 14 ibu. Pengumpulan data penelitian berupa skala pola pengasuhan otoritatif. Analisis data menggunakan $t$-test. Hasil penelitian menunjukkan bahwa "program excellent parenting" memiliki pengaruh positif terhadap peningkatan pola asuh otoritatif ibu. Penelitian ini menyimpulkan bahwa program excellent parenting bermanfaat bagi para ibu untuk meningkatkan pola asuh otoritatif.
\end{abstract}

Kata Kunci: Pola pengasuhan otoritatif, program excellent parenting, ibu

Pola pengasuhan yang ideal penting dimiliki orang tua agar mereka mampu mendidik, merawat serta membesarkan anak dengan lebih baik. Terutama pada anak usia pra-sekolah, mereka berada pada masa pertumbuhan, perkembangan serta pembentukan karakter yang memerlukan pendampingan orang tua (Powell et al.,
2012). Anak berusia 4-6 tahun berada pada tahap perkembangan inisiatif versus rasa bersalah (initiative vs. guilt) dimana anak melaksanakan segala sesuatu dengan belajar dari lingkungannya (Erickson, 1968, dalam Wu et al., 2002). Karena itu, pada tahap usia anak ini, pendampingan dari orang tua menjadi penting.

Korespondensi tentang artikel ini dapat dialamatkan kepada Rifa Hidayah melalui email: rifa_hidayah@psi.uin-malang.ac.id 
Ibu sebagai sosok penting yang berperan dalam mengasuh anak. Interaksi ibuanak yang menyenangkan penting dalam perilaku pengasuhan (Zhang et al., 2019). Karena itu, ibu perlu memiliki kemahiran dalam mengasuh anak yang berdampak positif pada kesejahteraan anak (Nunes et al., 2020). Penerapan pola pengasuhan pada anak harus dilandasi dengan kasih sayang, sebab kesalahan orang tua menerapkan pola asuh, dapat berakibat pada perilaku negatif pada anak (Liu, 2020). Keteladanan yang diberikan pada anak dalam berperilaku, merupakan bagian dari menerapkan pola pengasuhan yang ideal pada anak.

Pola pengasuhan berperan penting dalam perkembangan anak, dan banyak peneliti tertarik untuk melihat dampak pengasuhan terhadap perkembangan anak (Kuppens \& Ceulemans, 2019). Kegiatan pola pengasuhan dalam lingkungan keluarga berperan penting untuk mewujudkan keberhasilan tumbuh kembang anak (Li, 2014).

Berbagai upaya dilakukan untuk meningkatkan kemampuan ibu dalam mengasuh anak, salah satunya adalah melalui program pelatihan parenting. Pelatihan parenting berguna bagi orang tua untuk meningkatkan pemahaman, kemampuan serta keterampilan dalam pengasuhan anak (Byrne et al., 2013; Nunes et al., 2020), dan dapat memberikan dukungan sosial serta meningkatkan kesejahteraan pada keluarga (Sanders, 2019).

Pola asuh dapat disebut juga parental control (Baumrind, 1971), yang bermakna memelihara anak. Tujuannya agar ketika anak dididik anak dapat menyesuaikan diri terhadap harapan sosial yang bisa diterima secara baik dan layak (Baumrind, 2011). Pola asuh diartikan cara mendidik anak yang diberikan dengan kasih sayang dan berpengaruh kuat pada anak (Monks et al., 2006), intinya pola pengasuhan merupakan strategi dan cara orang tua merawat, mendidik serta membesarkan anak yang terbaik dengan penuh kasih sayang.
Pola pengasuhan orang tua terdiri atas tiga jenis (Baumrind, 1971). Pengasuhan pertama, yaitu pengasuhan orang tua secara otoriter, yaitu pola pengasuhan yang kurang responsif dalam mendidik anak. Orang tua mempraktikkan pola pengasuhan otoriter memprioritaskan rasa patuh pada orang tua, dan kurang memberi kebebasan anak. Orang tua sering memaksakan membentuk perilaku anak, agar sejalan dengan yang diinginkan orangtua, serta mengasuh dengan keras atau kaku kurang hangat dan jarang memuji anak jika berhasil (Porter et al., 2005). Dalam pengasuhan ini anak tidak bebas bersikap sehingga membuat anak memiliki ketergantungan pada orang tua dan kurang mandiri dalam bersikap, serta dalam praktek pola pengasuhan yang otoriter rentan mengalami abuse/pelecehan (Rizvi \& Najam, 2019).

Kedua, authoritative parenting style (pola pengasuhan otoritatif). Bagi orang tua yang menerapkan pola pengasuhan otoritatif, cara merawat dan mendidik anak dilaksanakan secara demokratis, memberikan kesempatan anak untuk mandiri dan bebas berperilaku namun dengan rasa tanggung jawab dan tetap dalam pengawasan orang tua (Baumrind, 2011). Misalnya mengenai penerapan aturan atau pendisiplinan, pada pola pengasuhan otoritatif, orang tua akan memberikan penjelasan pada anak mengapa cara semacam itu harus dilakukan. Dalam kehidupan sehari hari, orang tua menunjukkan kasih sayang terhadap anak, namun tetap tegas dalam aturan yang diperlukan. Selain itu orang tua membantu anak untuk mengutarakan pendapat dan memberikan kebebasan pada anak dalam membuat keputusan untuk dirinya sendiri. Orang tua mendidik anak secara tegas dan rasional, sering berkomunikasi dan berdiskusi dengan orang tua. Saat mengasuh, orang tua fleksibel dan responsif terhadap anak menunjukkan kelembutan, serta tidak kasar (Anjum et al., 2019; Su et al., 2017).

Pola asuh ketiga adalah permissive parenting style. Praktek pola asuh permisif 
dengan memberi kebebasan anak, tidak mengekang, anak bebas mengekspresikan perasaan tanpa memberi aturan, namun orang tua jarang mengontrol perilaku anak (Baumrind, 2011). Orang tua dalam pola pengasuhan ini cenderung longgar terhadap anak, tidak membatasi gerak anak dan menuruti keinginan anak. Dalam pola asuh ini anak jarang diawasi, dan sedikit saja dalam memberi tuntutan maupun menerapkan disiplin (Newman et al., 2015). Kelemahan dari pola asuh ini, akibat orang tua sering membebaskan anak dan tidak memberikan pengarahan, adalah anak bisa menjadi agresif (Anjum et al., 2019) atau anti sosial (Kuppens \& Ceulemans, 2019).

Pengasuhan yang dipraktekkan orang tua dapat berpengaruh terhadap perkembangan anak. Pola asuh yang dipandang paling tepat untuk perkembangan psikologis anak yang positif adalah pola pengasuhan otoritatif. Pola asuh otoritatif akan mendukung perkembangan harga diri anak karena anak akan lebih mudah menyesuaikan diri, kompeten, mempunyai kontrol diri yang baik (Baumrind, 2011). Pola pengasuhan otoritatif sangat baik di diterapkan sejak dini, dan memberi efek positif pada perilaku anak, mudah dalam bersahabat dan mudah menjalin kerjasama dengan orang lain, dan terhindar dari stres (Baumrind, 1971), serta anak akan menjadi lebih mandiri dan kreatif (Larson, 2000). Pemahaman orang tua yang baik mengenai pola asuh otoritatif lebih memudahkan mereka untuk menerapkannya pada saat mengasuh anak. Penelitian menunjukkan bahwa semakin orang tua mampu menerapkan pengasuhan otoritatif dengan baik, maka harga diri anak menjadi lebih baik (Mentari \& Daulima, 2017), serta berkurangnya risiko persaingan antara saudara ( $\mathrm{Yu} \&$ Gamble, 2008).

Berbagai penelitian terhadap pola pengasuhan otoritatif orang tua menunjukkan bahwa pola pengasuhan tersebut dapat mempengaruhi perilaku prososial (Farid, 2011), dan kecerdasan emosi (Muarifah \& Puspitasari, 2018). Penelitian Newman et al. (2015) di beberapa negara (Cina, Turki dan Amerika) menunjukkan bahwa pola asuh otoritatif berhubungan positif dengan prestasi di sekolah dan harga diri anak. Kolaborasi orang tua dan guru di sekolah dalam program pembelajaran di sekolah sangat berguna bagi anak. Orangtua yang memperlakukan anak dengan baik maka anak juga lebih mudah dididik, namun jika perhatian orang tua tidak cukup maka anak juga merasa kurang kasih sayang.

Pola asuh otoritatif pertama kali diajukan oleh Baumrind (1971) dengan ciri utama orang tua berwibawa dan saling menghargai, adanya kontrol orang tua dan menghormati otonomi anak serta kebebasan anak (Su et al., 2017). Terdapat tiga dimensi pola asuh otoritatif merujuk kepada Baumrind (1971) seperti yang dikembangkan dalam alat ukur PSDQ oleh Porter (2005), Su (2017) dan Wu (2002), yaitu: 1) memberi kehangatan dan penerimaan (koneksi), yakni hubungan emosional anak dan orang tua terjalin secara positif. Contohnya, orang tua memberikan pujian secara tepat, memberikan kenyamanan, dan menunjukkan pengertian pada anak, serta memiliki koneksi kehangatan, menyayangi anak, dengan cara memeluk, mencium, dan menggendong anak; 2) memberi otonomi psikologis yang tinggi. Orang tua memberikan penjelasan atau alasan kepada anak mengapa aturan harus ditaati dan mengapa perilaku ada yang tidak boleh dilakukan. Orang tua memberikan penjelasan kepada anak mengenai baik buruknya perilaku; 3) partisipasi demokratis atau pemberian otonomi, yaitu memberikan kesempatan kepada anak untuk memberi masukan ke dalam aturan keluarga (Porter et al., 2005; Su et al., 2017; Wu et al., 2002).

Perkembangan dan sosial emosional anak pada awal tahun kehidupan, dipengaruhi oleh gaya interaksi yang mereka miliki dengan ibu (Bronfenbrenner \& Evans, 2000). Membesarkan anak hingga dewasa membutuhkan pengabdian orang tua serta pengetahuan yang dibutuhkan (Baumrind, 2011). Salah satu pihak keluarga yang ber- 
peran dalam pengasuhan selain ayah sebagai kepala rumah tangga juga ada ibu. Ibu yang mengasuh anak secara berkualitas diperlukan bagi pemberian pengasuhan yang terbaik bagi anak (McKinney \& Renk, 2008; Su et al., 2017). Mengingat ibu adalah sosok yang penting dalam memberikan pengasuhan pada anak (Kim \& Chang, 2019), maka program parenting bagi ibu perlu diteliti. Berdasarkan alasan tersebut, penelitian kali ini bertujuan untuk menguji pengaruh dari program excellent parenting dalam meningkatkan pola asuh otoritatif ibu.

Penelitian terhadap program parenting sebelumnya telah dilakukan. Indrawati (2020) meneliti efektivitas dari program positive parenting untuk menurunkan stres ibu dalam mengasuh anak. Annisa (2016) menguji program home start parenting terhadap emosi Ibu saat mengasuh anak. Rozana dkk (2018), meneliti smart parenting demokratis dalam membangun karakter anak.

Penelitian ini berbeda dari penelitian sebelumnya karena mengambil fokus pada peningkatan pola asuh otoritatif ibu. Selain itu, beberapa penelitian sebelumnya belum mempertimbangkan tingkat pendidikan ibu. Misalnya, penelitian Annisa (2016) memakai non probability sampling sebagai strategi memilih subjek penelitian, namun tingkat pendidikan subjek tidak dipertimbangkan. Dalam penelitian ini, tingkat pendidikan subjek dijadikan bahan pertimbangan penting. Penelitian sebelumnya memiliki subjek yang berbeda dengan penelitian ini, misalnya Mubarok (2016) yang meneliti program parenting positif pada orang tua yang memiliki anak remaja, sedangkan penelitian saat ini subjeknya adalah ibu-ibu yang memiliki anak sekolah di Taman Kanak-kanak (TK).

Penelitian untuk meneliti efektivitas program excellent parenting yang spesifik meningkatkan pola pengasuhan otoritatif penting dilakukan karena pola pengasuhan otoritatif terbukti, berdasarkan hasil penelitian sebelumnya, dapat berdampak positif bagi perkembangan psikologis anak.

Pelatihan parenting mencakup pemberian layanan pengetahuan, pengembangan keterampilan, peningkatan kompetensi, dan dukungan pengasuhan kepada orang tua (Cowen, 2001) yang berbentuk individual atau kelompok (Chen \& Chan, 2016). Secara umum, ada dua jenis program parenting yaitu kunjungan ke rumah dan pendidikan orang tua atau pelatihan (Holzer et al., 2006). Dalam penelitian ini, program excellent parenting pada ibu-ibu berupa pelatihan untuk meningkatkan kualitas penerapan pola pengasuhan anak secara otoritatif dengan materi pengasuhan yang terbaik, termasuk strategi penerapan pola asuh otoritatif.

Pola pengasuhan otoritatif diidentikkan dengan pengasuhan yang memberikan sepenuhnya dukungan kepada anak, aturan orang tua terhadap anak tidak ketat namun orang tua tetap melatih disiplin secara konsisten, tegas sesuai dengan tumbuh kembang anak, sosial, pendidikan, kognitif dan emosi positif pada anak (Winsler et al., 2005). Ibu yang memiliki anak yang sedang belajar di TK dipilih karena pada tahap ini perkembangan anak dipengaruhi oleh lingkungan di sekitarnya terutama lingkungan mikrosistem (Bronfenbrenner, 1986). Dalam hal ini, ibu berperan dalam memberikan pengasuhan dan pemberian stimulasi. Peran orang tua (misalnya peran ibu) dalam memberikan teladan pada anak sangat diperlukan dalam membentuk lingkungan keluarga yang harmonis. Terbentuknya perilaku yang baik pada anak melalui praktek pola pengasuhan otoritatif memerlukan timbal balik saling menghargai antara orangtua dan anak, termasuk mengenalkan dan mengajari anak emosi positif sejak dini, apalagi pola pengasuhan otoritatif berkorelasi positif secara signifikan dengan kognitif positif dan regulasi emosi (Liu, 2020).

Berdasarkan fenomena tersebut, maka penelitian program excellent parenting bagi ibu untuk meningkatkan pola pengasuhan otoritatif penting dilakukan. Para ibu ke- 
mungkinan besar memiliki interaksi paling konstan dengan anak-anak pada setiap tahap perkembangan anak (Li et al., 2010). Hipotesis penelitian ini adalah program excellent parenting dapat meningkatkan pola pengasuhan otoritatif ibu.

\section{Metode}

Penelitian ini menguji pengaruh dari program "excellent parenting" terhadap peningkatan pola pengasuhan otoritatif pada ibu. Desain penelitian menggunakan kuasi-eksperimen, dengan satu kelompok eksperimen tanpa adanya kelompok kontrol (Kerlinger, 2004). Variabel bebasnya ialah program excellent parenting, dan pola pengasuhan otoritatif sebagai variabel terikat.

\section{Subjek}

Subjek penelitian sebanyak 14 orang, yaitu ibu yang memiliki anak sekolah di Taman kanak-kanak "DWP" kelas A dan B Dau Malang. Usia subjek penelitian antara 25-37 tahun, menempuh pendidikan SD sampai SMA. Alasan pemilihan subjek yang memiliki anak yang sedang belajar di TK adalah: pertama, anak TK berada pada tahap masa kanak-kanak awal yang sangat penting untuk menanamkan karakter positif anak; kedua, lembaga pendidikan TK membutuhkan adanya pendampingan pada orang tua siswa agar dapat diajak bekerjasama dalam peningkatan kualitas pribadi yang sehat para siswanya sekaligus menanamkan kebiasaan positif pada anak.

Sebelum dilaksanakan penelitian, subjek penelitian diminta untuk mengisi lembar persetujuan (consent form) menjadi peserta pelatihan. Berdasarkan isian lembar persetujuan, terdapat 20 subjek (ibu) yang bersedia mengikuti kegiatan program excellent parenting. Nnamun, dari 20 subjek tersebut, yang sesuai kriteria dan bisa mengikuti seluruh rangkaian pelatihan excellent parenting adalah berjumlah 14 orang.

\section{Pengumpulan Data}

Pola pengasuhan otoritatif merupakan perawatan, pemeliharaan orang tua secara demokratis kepada anak melalui dukungan penuh pada anak, namun orang tua tetap mengawasi serta melatih disiplin anak secara konsisten. Skala pola asuh otoritatif disusun peneliti berdasarkan dimensi alat ukur PSDQ yang dikembangkan oleh Porter (2005), Su (2017) dan Wu (2002) yang terdiri atas tiga dimensi, yaitu: 1) memberi kehangatan, pengasuhan, dan penerimaan; 2) pemberian otonomi psikologis, penalaran-regulasi; dan 3) partisipasi demokratis. Skala pola asuh otoritatif terdiri atas 24 aitem pernyataan dengan lima alternatif jawaban; (1). STS (sangat tidak setuju), skor satu, (2). Jika menjawab TS (tidak setuju) mendapat skor dua, (3). N (netral) skor tiga, (4). Skornya empat jika menjawab S (setuju), (5). Memperoleh skor lima, jika menjawab SS (sangat setuju).

Reliabilitas hasil uji coba skala pola pengasuhan otoritatif terhadap 30 subjek menghasilkan alpha cronbach dari skala pola asuh otoritatif sebesar 0,941 , dan daya beda aitem pada skala pola asuh antara 0,311-824. Hasil estimasi reliabilitas dari semula 24 item terdapat 23 item punya daya beda tinggi, dan 1 item punya daya beda rendah. Item yang valid memiliki nilai $\mathrm{p}<0,05$ serta korelasinya positif.

Program Excellent parenting merupakan suatu bentuk pelatihan parenting yang diberikan kepada ibu-ibu dengan cara penyampaian materi peranan penting orang tua dan langkah-langkah mengasuh dan mendidik anak sejak dını, memahami dinamika perkembangan anak, dan peran penting komunikasi dan hubungan emosional positif anak dan orangtua, penerapan pola asuh otoritatif, serta pemberian konseling dan simulasi problem solving pola pengasuhan anak.

\section{Prosedur}

Pelaksanaan penelitian melibatkan ke- 
kelompok eksperimen yang mendapat program excellent parenting. Sebelum dilaksanakan eksperimen para subjek penelitian diminta untuk mengisi angket pola asuh otoritatif dan identitas subjek dan anak. Pengisian skala pola asuh otoritatif (pretest) dengan tujuan untuk melihat skor pola pengasuhan otoritatif sebelum dilakukan eksperimen. Penelitian eksperimen "program excellent parenting" dilaksanakan dalam lima sesi. Pelaksanaan kegiatan excellent parenting masing-masing sesi berlangsung 80 menit. Program excellent parenting dilakukan melalui kegiatan presentasi dan diskusi, sharing (berbagi pengalaman), konseling, review materi dan lembar evaluasi, dalam rangka peningkatan pola pengasuhan otoritatif ibu. Materi utama program excellent parenting tertuang pada Tabel 1.

Tabel 1. Materi program excellent parenting

\begin{aligned} & \hline Sesi \multicolumn{1}{c}{ Materi } \\ & \hline Pertama $\begin{array}{l}\text { Peranan penting orang tua dalam } \\ \text { mengasuh dan mendidik anak } \\ \text { Kedua }\end{array} \\ & \begin{array}{l}\text { Langkah-langkah dalam } \\ \text { memelihara dan mengasuh anak } \\ \text { sejak dinı }\end{array} \\ &$ Ketiga $\begin{array}{l}\text { Memahami dinamika } \\ \text { perkembangan anak, peran } \\ \text { penting komunikasi dan } \\ \text { hubungan emosional positif anak } \\ \text { dan orangtua } \\ \text { Menanamkan pola pengasuhan } \\ \text { otoritatif }\end{array} \\ &$ Keempatima $\begin{array}{l}\text { Konseling "problem solving pola } \\ \text { pengasuhan anak" }\end{array} \\ &$\hline\end{aligned}

Setelah berakhirnya program, subjek penelitian diminta kembali untuk mengisi skala pola asuh otoritatif (posttest) dengan tujuan untuk mengukur kembali skor pola pengasuhan otoritatif subjek. Skala pola asuh otoritatif yang digunakan saat pretest sama dengan skala pola asuh yang digunakan untuk posttest, yaitu skala pola asuh otoritatif untuk pretest dipakai juga untuk mengukur mengukur kembali (post- test) pola asuh otoritatif subjek. Namun, untuk menghindari bias maka urutan nomor item pada skala pola asuh otoritatif pretest dan posttest berbeda.

\section{Analisis data}

Analisis data untuk melihat pengaruh program excellent parenting terhadap peningkatan pola pengasuhan otoritatif ibu dilakukan dengan t-test menggunakan program IBM SPSS 22 for Windows. Uji asumsi dilakukan terlebih dahulu sebelum uji $t$-test. Hasil uji asumsi berupa uji homogenitas dan normalitas. Uji analisis prasyarat berupa uji normalitas data penelitian menggunakan uji shapiro-wilk. Nilai signifikansi uji normalitas p pretest $=0.939$, dan $\mathrm{p}$ posttest sebesar $0.872(\mathrm{p}>0.05)$. Berdasarkan analisis data diketahui, bahwa data pola pengasuhan otoritatif berdistribusi normal. Hasil signifikansi uji homogenitas, melalui uji Levene sebesar 0.124 $(p>0.05)$, artinya varians data penelitian adalah homogen, dengan dipenuhi uji asumsi tersebut maka dipilih, Teknik $t$-test untuk uji hipotesis penelitian.

\section{Hasil}

\section{Data Deskriptif}

Penelitian melibatkan 14 ibu orang berjenis kelamin perempuan, dan memiliki anak yang sekolah di TK dengan usia subjek 25-37 tahun. Jenjang pendidikan subjek meliputi; 5 orang lulusan Sekolah Dasar, 2 orang berpendidikan SMP, dan 7 orang pendidikan SMA. Pekerjaan subjek meliputi: 2 sebagai karyawan swasta dan 12 sebagai ibu rumah tangga.

Data skor pretest pola pengasuhan otoritatif subjek dan skor posttest pola pengasuhan otoritatif dianalisis menggunakan statistik deskriptif untuk memaparkan jumlah data penelitian. Berdasarkan hasil analisis statistik deskriptif diperoleh data skor minimal pretest 58 dan skor maksimal pretest 106, skor minimal posttest 76 dan 
skor maksimal post-test 107. Nilai rerata pretest 82.36, dan posttest 91.57 .

\section{Uji Hipotesis}

Hipotesis penelitian untuk melihat perbedaan rata-rata skor pola asuh otoritatif ibu sebelum eksperimen dan setelah eksperimen dianalisis melalui paired sample $t-$ test. Hasil analisis data tertera di Tabel 2.

Tabel 2. Hasil Uji-t

\begin{tabular}{lcccc}
\hline & Mean & t & df & Sig. \\
\hline $\begin{array}{l}\text { Posttest - } \\
\text { Pretest }\end{array}$ & 9.214 & 6.034 & 13 & 0,00 \\
\hline
\end{tabular}

Analisis data hasil $t$-test sesuai Tabel 2 diperoleh nilai $\mathrm{t}=6.034$, sedangkan hasil uji signifikansi p sebesar $0.000(\mathrm{p}<0.05)$ menunjukkan hipotesis diterima, yang berarti ada perbedaan skor pola asuh otoritatif sebelum eksperimen dan setelah dilakukan eksperimen. Hasil ini menunjukkan ada pengaruh program excellent parenting terhadap pola asuh otoritatif ibu. Untuk melihat berapa besar peningkatan skor pola asuh otoritatif ibu dilihat dari rata-rata skor pola asuh otoritatif sebelum dan setelah eksperimen program excellent parenting sebagaimana tercantum dalam Tabel 3.

Tabel 3. Rerata Skor Pola Asuh Otoritatif Sebelum dan Setelah Eksperimen

\begin{tabular}{llllll}
\hline $\begin{array}{l}\text { Keg- } \\
\text { Tes }\end{array}$ & N & $\begin{array}{l}\text { Mini- } \\
\text { Mum }\end{array}$ & $\begin{array}{l}\text { Mumi- } \\
\text { Mum }\end{array}$ & Rerata & SD \\
\hline Pretest & 14 & 58 & 106 & 82.36 & 13.636 \\
Posttest & 14 & 76 & 107 & 91.57 & 9.121
\end{tabular}

Gambaran peningkatan rerata skor pola asuh otoritatif subjek antara sebelum dan setelah eksperimen terilustrasikan pada Grafik 1. Rerata skor pretest pola pengasuhan otoritatif ibu sesuai Tabel 3 dan Grafik 1, diperoleh 82.36, dan rerata skor posttest 91.57 . Skor rerata pola asuh oto-
Grafik 1. Peningkatan Rerata Skor Pola Asuh Otoritatif Sebelum dan Setelah eksperimen

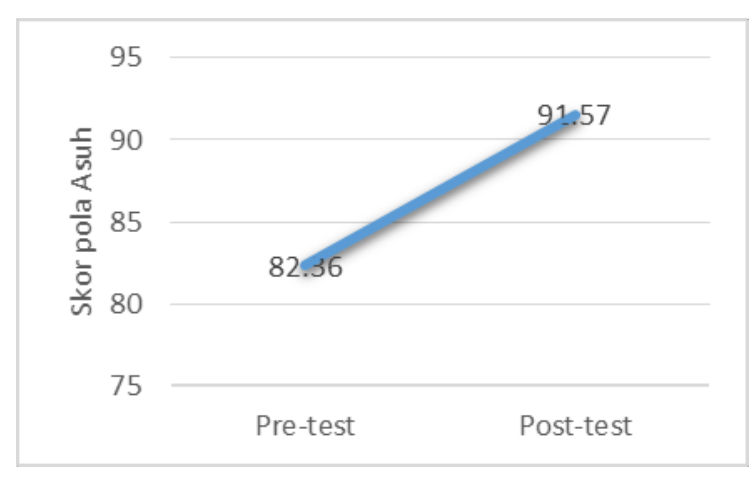

otoritatif meningkat sebanyak 9.21 point. Artinya ada peningkatan skor pola asuh pada subjek setelah eksperimen secara signifikan. Hasil uji hipotesis sesuai Tabel 2 dan 3 menunjukkan bahwa hipotesis penelitian ini, yaitu program excellent parenting dapat meningkatkan pola pengasuhan otoritatif ibu adalah dapat diterima. Hasil penelitian membuktikan ada peningkatan pola pengasuhan otoritatif subjek setelah mengikuti eksperimen program excellent parenting.

\section{Pembahasan}

Hasil penelitian telah membuktikan adanya peningkatan pola pengasuhan otoritatif ibu setelah dilakukan eksperimen yang berupa program excellent parenting Meningkatnya pola pengasuhan otoritatif ibu dalam mendidik anak dengan tepat membantu orang tua dalam mendidik anak, cara menanamkan karakter positif pada anak, dan bertambah kepedulian orangtua mendidik anak secara lebih baik. Penelitian ini mengkonfirmasi penelitian sebelumnya mengenai studi orang tua yang mengasuh secara otoritatif, akan lebih peduli pada anak sehingga memudahkan orang tua menanamkan karakter positif pada anak dengan tetap memperhatikan nilai-nilai di masyarakat (Su et al., 2017). Orang tua yang mendidik anak secara otoritatif menjalin komunikasi dengan hangat, memberikan bimbingan kepada anak, dan ada pola penjelasan mengapa anak taat konse- 
kuensinya, serta mendorong anak berprestasi (Newman et al., 2015). Kebutuhan kasih sayang secara psikologis menjadi dambaan anak. Orang tua yang memahami bagaimana mempraktikkan pengasuhan otoritatif memberikan kebebasan anak berperilaku, tapi tetap orang tua memonitor dan punya kendali untuk anak, dengan saling menghargai dan menciptakan keharmonisan dalam keluarga. Sehingga muncul saling terbuka dalam berpendapat, nantinya anak lebih lebih mandiri dan bertanggung jawab dalam memecahkan masalah dalam kehidupannya (Winsler et al., 2005).

Ibu sebagai bagian dari keluarga yang memahami pola asuh otoritatif akan menerapkan pemahamannya dalam mendi-dik anak, dengan tanggung jawab dan kasih sayang yang tulus. Orang tua termasuk ibu sebaiknya mencontohkan keteladanan terbaik bagi anak, karena sebagai pendidik dalam keluarga, orang tua dituntut untuk menanamkan karakter dan nilai kemanusian yang terbaik yang kelak menjadi bekal perkembangan anak (Baumrind, 2011). Anak yang diasuh dengan penghargaan dan penanaman perilaku yang baik melalui pola pengasuhan otoritatif akan memiliki harga diri yang tinggi, dan memiliki kemampuan bersosialisasi lebih baik, sehingga terhindar dari gangguan perilaku negatif (Newman et al., 2015).

Penerapan pola pengasuhan otoritatif memudahkan bagi keluarga untuk membina hubungan dengan saling menerima, memahami dan memberi serta aturan yang diberikan orang tua, sehingga terjalin komunikasi dengan anak secara lebih baik baik termasuk konsekuensinya (Byrne et al., 2013). Pengasuhan otoritatif membawa anak pada perilaku yang baik, dan mampu bersahabat dan bekerja sama dengan baik, serta bisa terhindar dari stres (Baumrind, 2011).

Membiasakan perilaku baik pada anak akan menguntungkan bagi anak untuk bekal masa depan kelak, anak akan mudah diterima di masyarakat karena memiliki perilaku yang baik, apalagi pola asuh otoritatif berkorelasi negatif dengan resiko perilaku negatif (health risk behaviors) seperti agresivitas, bunuh diri (Liu, 2020). Anak yang memiliki sikap yang baik dan karakter yang yang positif memudahkan anak untuk bergaul sehingga anak merasa senang banyak teman dan tidak salah bergaul dan terhindar dari perilaku negatif (Newman et al., 2015; Baumrind, 2011).

Orang tua berperan penting dalam melibatkan diri dalam pengasuhan pada anak, kehadiran orang tua dalam kehidupan anak tak tergantikan, yang pada akhirnya membentuk pola asuh yang ditanamkan pada anak. Selain ayah, keberadaan ibu sangat berperan dalam pola pengasuhan di keluarga, dan seorang Ibu yang mampu menempatkan diri dalam keluarga dengan baik membawa dampak positif dalam keharmonisan hubungan keluarga.

Berdasarkan hasil penelitian ini, dapat dikonfirmasi beberapa wawasan teoritis sebagai berikut. Pertama, orang tua menerapkan berbagai kegiatan yang terbaik dalam pengasuhan anak, mengutamakan merawat anak dengan kelembutan, kasih sayang yang tulus dan menciptakan keluarga yang harmonis (Byrne et al., 2013). Mengasuh anak dengan kasih sayang berdampak pada aspek perkembangan dan psikologis anak, yaitu akan menjadi anak yang berperilaku baik dan mudah diterima di masyarakat (Papalia et al., 2013). Kasih sayang tulus orang tua diharapkan anak, begitu pula dukungan orang tua sangat berarti bagi anak-anak nya. Harapan orang tua yang terbaik untuk masa depan anak merupakan doa dan penyemangat anak dalam kehidupannya, hal ini terkait juga dengan efikasi orang tua. Efikasi diri anak yang lebih tinggi terkait dengan tingkat dukungan sosial orang tua yang lebih tinggi pula (Ontai et al., 2008).

Kedua, pengasuhan yang baik perlu memberikan kenyamanan pada anak dalam keluarga. Rasa aman dan nyaman yang diberikan orang tua dalam pengasuhannya akan membuat anak tenang dan nyaman serta memiliki komunikasi yang baik, 
sehingga anak tidak merasa ketakutan untuk menyampaikan keinginan dan orang tua juga bisa mengabulkan keinginan yang baik sesuai dengan kemampuan orang tua serta mengarahkannya jika hal tersebut dirasa kurang baik, sehingga anak akan nyaman dan tidak mengalami kecemasan. Rasa nyaman dan aman yang diberikan orang tua melalui jalinan komunikasi yang baik, merawat anak dengan kelembutan dan menghindari marah terhadap anak, hal tersebut akan mempermudah orang tua memotivasi anak, yang kelak anak dapat mengikuti standar orang tua yang sesuai dengan arahan orang tua (Rudy \& Grusec, 2001). Ketiga, menciptakan kedekatan emosional dengan anak secara kualitas dan kuantitas, artinya kehadiran ayah dan ibu di rumah bersama anak bukan hanya sekedar hadir namun memberikan pengasuhan yang berkualitas sesuai dengan kebutuhan anak. Kesiapan menjadi orang tua ayah dan ibu diperlukan dan dapat mempengaruhi kuantitas dan kualitas pengasuhan orang tua. Jika orang tua tidak memiliki pemahaman bagaimana mengasuh anak dengan baik, dan ketidakmampuan mereka untuk berhasil memenuhi peran mereka sebagai orang tua maka kehidupan anak di kemudian hari dapat menimbulkan perilaku bermasalah (Anjum et al., 2019).

Keempat, pengasuhan yang baik dapat menciptakan keharmonisan dalam keluarga. Upaya mencapai keharmonisan dalam keluarga mengurangi pertikaian dan menjaga lingkungan kondusif yang membuat anak nyaman. Orang tua menyayangi anak dengan penuh kehangatan, dan memberikan perhatian penuh pada anak. Orang tua mendukung keinginan dan cita-cita anak.

Penelitian ini dapat melengkapi studi sebelumnya, namun masih memiliki keterbatasan, antara lain; pertama, studi ini tidak melibatkan kelompok kontrol dalam penelitian, dan hanya ada satu kelompok eksperimen, sehingga nantinya perlu dimasukkan kelompok kontrol. Selain itu, dibutuhkan studi yang lebih komprehensif dan mendalam mengenai pengaruh dari faktor lain terhadap pola pengasuhan orang tua.

Kedua, subjek penelitian ini hanya melibatkan ibu. Padahal pelibatan ayah dalam pengasuhan adalah sangat penting. Perilaku pengasuhan ibu lebih positif jika mendapat dukungan emosional dari ayah (Zhang et al., 2019). Ke depan, diharapkan program excellent parenting bukan hanya terbatas pada ibu saja tetapi juga ayah karena keseimbangan pola pengasuhan ayah dan ibu dalam keluarga menjadi krusial dalam masa tumbuh kembang anak.

Ketiga, penelitian ini memilih subjek yang memiliki anak terbatas pada usia TK, dengan jumlah subjek sedikit, hanya 14 orang. Sebaiknya juga melibatkan orang tua memiliki anak diusia balita, PAUD, dan SD. Oleh karena itu, dibutuhkan penelitian yang lebih komprehensif dan mendalam mengenai pola pengasuhan anak. Dengan demikian, akan diperoleh pemahaman yang lebih luas mengenai konsepsi serta program parenting apa saja yang bisa meningkatkan pola pengasuhan anak.

Keempat, pengukuran posttest hasil eksperimen hanya dilakukan satu kali, sebaiknya untuk melihat dampak program excellent parenting lebih baik dilakukan follow-up jangka panjang dan lebih dari satu kali pengukuran.

\section{Simpulan dan Saran}

Hasil penelitian menunjukkan, bahwa program excellent parenting mampu meningkatkan pola asuh otoritatif pada ibu. Berdasarkan hasil penelitian, setidaknya terdapat beberapa hal penting yang perlu dikembangkan oleh penelitian berikutnya.

Penelitian selanjutnya dapat berfokus pada pengembangan program parenting dengan melibatkan ayah dan ibu karena kualitas pola pengasuhan terhadap anak banyak ditentukan oleh keselarasan pola asuh ayah dan ibu. Selain itu, keberlang- 
sungan pengasuhan di tingkat keluarga sebagai sebuah sistem menjadi prasyarat penting dalam pembentukan psikologis yang positif pada anak. Karena itu, perlu dilakukan penelitian dasar atau pengembangan dalam topik pengasuhan berdasarkan perspektif keluarga sebagai sistem ekologis.

\section{Daftar Pustaka}

Anjum, A., Noor, T., \& Sharif, N. (2019). Relationship Between Parenting Styles and Aggression in Pakistani Adolescents. Khyber Medical University Journal, 11(2), 98-101. https://doi.org/10.35845/kmuj.2019.1 8568

Annisa, Y. N. (2016). Home-Start Parenting Program untuk Meningkatkan Fungsi Emosi Ibu dalam Pengasuhan Anak Usia Dini. Psympathic : Jurnal Ilmiah Psikologi, 3(1), $1-22$. https://doi.org/10.15575/psy.v3i1.109 6

Batool, S. S., \& Bond, R. (2015). Mediational role of parenting styles in emotional intelligence of parents and aggression among adolescents. International Journal of Psychology, 50(3), 240-244. https://doi.org/10.1002/ijop.12111

Baumrind, D. (1971). Current patterns of parental authority. Developmental Psychology, 4(1 PART 2), 1-103. https://doi.org/10.1037/h0030372

Baumrind, D. (2011). Effects of Authoritative Parental Control. Child Development, 37(4), 887-907. https://doi.org/https://doi.org/10.2307/ 1126611

Bronfenbrenner, U. (1986). Ecology of the family as a context for human development: Research perspectives. Developmental Psychology, 22(6), 723-742.

https://doi.org/10.1037/0012-

1649.22.6.723
Bronfenbrenner, U., \& Evans, G. W. (2000). Developmental Science in the 21st Century: Emerging Questions, Theoretical Models, Research Designs and Empirical Findings. Social Development, 9(1), 115-125. https://doi.org/10.1111/14679507.00114

Byrne, S., Salmela-Aro, K., Read, S., \& Rodrigo, M. J. (2013). Individual and Group Effects in a Community-Based Implementation of a Positive Parenting Program. Research on Social Work Practice, 23(1), 46-56. https://doi.org/10.1177/104973151245 7831

Chen, M., \& Chan, K. L. (2016). Effects of Parenting Programs on Child Maltreatment Prevention: A MetaAnalysis. Trauma, Violence, and Abuse, 17(1), 88-104. https://doi.org/10.1177/152483801456 6718

Cowen, P. S. (2001). Effectiveness of a parent education intervention for atrisk families. In Journal of the Society of Pediatric Nurses: JSPN (Vol. 6, Issue 2, pp. 73-82). https://doi.org/10.1111/j.17446155.2001.tb00124.x

Farid, M. (2011). Hubungan penalaran moral, kecerdasan emosi, religiusitas, dan pola asuh orangtua otoritatif dengan perilaku prososial remaja. Disertasi. Tidak diterbitkan. UGM: Yogyakarta.

Holzer, P. J., Higgins, J. R., Bromfield, L. M., Richardson, N., \& Higgins, D. J. 
(2006). The effectiveness of parent education and home visiting child maltreatment prevention programs. Child Abuse Prevention Issues, 24, 124. http://www.aifs.gov.au/nch

Indrawati, T. (2020). Efektivitas Program Positif Parenting Dalam Mengurangi Stres Pengasuhan pada Ibu Muda. AlAthfaal: Jurnal Ilmiah Pendidikan Anak, 2(3), 201-215. http://ejournal.radenintan.ac.id/index. php/al-athfaal/article/view/7251

Kerlinger, F. N. (2004). Asas-asas Penelitian Behavioural (terjemahan); Yogyakarta: Gadjah Mada University Press.

Kim, H.-J., \& Chang, Y. E. (2019). The Relationship between Job-Role Quality and Parenting Behaviors among Employed Mothers in Korea Author ( $\mathrm{s}$ ): Young Eun Chang and Hee-Jin Kim Source: Journal of Comparative Family Studies, Vol . 47 , No . 4 ( AUTUMN 2016 ), pp . 527548 Published by: Journal of Comparative Family Studies, 47(4), 527-548.

https://www.jstor.org/stable/44109643

Kuppens, S., \& Ceulemans, E. (2019). Parenting Styles: A Closer Look at a Well-Known Concept. Journal of Child and Family Studies, 28(1), 168181. https://doi.org/10.1007/s10826018-1242-x

Larson, R. W. (2000). Toward a Psychology of Positive Youth Development. American Psychologist, 55(1), 170-183. doi: 10.1037//0003066x.55.1.170

Li, S. D. (2014). Familial Religiosity, Family Processes, and Juvenile Delinquency in a National Sample of Early Adolescents. Journal of Early Adolescence, 34(4), 436-462. https://doi.org/10.1177/ 0272431613495445.
Li, Spencer D. (2011). The religious context of parenting, family processes, and alcohol use in early adolescence. Journal of Drug Issues, 41(4), 619-648. https://doi.org/10.1177/002204261104 100408

Li, Y., Costanzo, P. R., \& Putallaz, M. (2010). Maternal socialization goals, parenting styles, and social-emotional adjustment among Chinese and European American young adults: Testing a mediation model. Journal of Genetic Psychology, 171(4), 330-362. https://doi.org/10.1080/00221325.201 0.505969

Liu, X. (2020). Parenting Styles and Health Risk Behavior of Left-Behind Children: The Mediating Effect of Cognitive Emotion Regulation. Journal of Child and Family Studies, 29(3), 676-685. https://doi.org/10.1007/s10826-01901614-2

McKinney, C., \& Renk, K. (2008). Differential Parenting Between Mothers and Fathers Implications for Late Adolescents. Journal of Family Issues, 29(6), 806-827. https://doi.org/10.1177/0192513X073 11222

Mentari, P., \& Daulima, N. H. C. (2017). Hubungan Pola Asuh Orangtua Dan Harga Diri Anak Jalanan Usia Remaja. Jurnal Keperawatan Indonesia, 20(3), 158-167. https://doi.org/10.7454/jki.v20i3.630

Monks, F. J., Knoers, A. M. P., \& Haditono, S. R. (2006). Psikologi perkembangan: Pengantar dalam berbagai bagiannya (terjemahan) Ed.3; Cet.ke-16. Yogyakarta: Gadjah Mada University Press.

Muarifah, A., \& Puspitasari, I. (2018). Hubungan Antara Pola Asuh Demokratis Dan Kecerdasan Emosi 
Dengan Persaingan Antar Saudara. Jurnal Psikologi Insight, 2(1), 1-10. https://doi.org/https://doi.org/10.1750 9/insight.v2i1.11919

Newman, J., Gozu, H., Guan, S., Lee, J. E., Li, X., \& Sasaki, Y. (2015). Relationship between Maternal Parenting Style and High School Achievement and Self- Esteem in China, Turkey and U . S . A . Author ( s ): Joan Newman, Hamide Gozu , Shuyi Guan, Ji Eun Lee, Xian Li and Yuriko Sasaki Source: Journal of Comparative Fami. Journal of Comparative Family, 46(2), 265-288. http://www.jstor.org/stable/43613115

Nunes, C., Martins, C., Ayala-Nunes, L., Matos, F., Costa, E., \& Gonçalves, A. (2020). Parents' perceived social support and children's psychological adjustment. Journal of Social Work. https://doi.org/10.1177/146801732091 1614

Ontai, L., Sano, Y., Hatton, H., \& Conger, K. J. (2008). Low-income rural mothers' perceptions of parent confidence: The role of family health problems and partner status. Family Relations, 57(3), 324-334. https://doi.org/10.1111/j.17413729.2008.00503.x

Pajar Mubarok, P. (2016). Program Pengasuhan Positif untuk Meningkatkan Keterampilan Mindful Parenting Orangtua Remaja. Psympathic: Jurnal Ilmiah Psikologi, 3(1), 35-50. https://doi.org/10.15575/psy.v3i1.109 5

Papalia, D. E., Olds, S. W., \& Feldman, R. D. (2013). Human Development. Perkembangan Manusia. Jakarta: Salemba Humanika.

Porter, C. L., Hart, C. H., Yang, C., Robinson, C. C., Olsen, S. F., Zeng, Q., Olsen, J. A., \& Jin, S. (2005). A comparative study of child temperament and parenting in Beijing, China and the western United States. International Journal of Behavioral Development, 29(6), 541-551. https://doi.org/10.1080/016502505001 47402

Powell, D. R., Son, S. H., File, N., \& Froiland, J. M. (2012). Changes in parent involvement across the transition from public school prekindergarten to first grade and children's academic outcomes. Elementary School Journal, 113(2), 276-300.

https://doi.org/10.1086/667726

Rizvi, S. F. I., \& Najam, N. (2019). Parenting styles and family demographic factors as predictors of abusive parenting among adolescents. Pakistan Journal of Psychological Research, 34(2), 277-297. https://doi.org/10.33824/PJPR.2019.3 4.2 .15

Rozana, A. A., Wahid, A. H., \& Muali, C. (2018). Smart Parenting Demokratis Dalam Membangun Karakter Anak. Al-Athfal: Jurnal Pendidikan Anak, 4(1), 1-16. https://doi.org/10.14421/alathfal.2018.41-01

Rudy, D., \& Grusec, J. E. (2001). Correlates of authoritarian parenting in individualist and collectivist cultures and implications for understanding the transmission of values. Journal of Cross-Cultural Psychology, 32(2), 202-212. https://doi.org/10.1177/002202210103 2002007

Sanders, M. R. (2019). Harnessing the Power of Positive Parenting to Promote Wellbeing of Children, Parents and Communities over a Lifetime. Behaviour Change, 36(2), 56-74.

https://doi.org/10.1017/bec.2019.3 
Sangawi, H., Adams, J., \& Reissland, N. (2018). The impact of parenting styles on children developmental outcome: The role of academic self-concept as a mediator. International Journal of Psychology, 53(5), 379-387. https://doi.org/10.1002/ijop.12380

Su, H., Cuskelly, M., Gilmore, L., \& Sullivan, K. (2017). Authoritative Parenting of Chinese Mothers of Children with and without Intellectual Disability. Journal of Child and Family Studies, 26(4), 1173-1183. https://doi.org/10.1007/s10826-0160628-x

Winsler, A., Madigan, A. L., \& Aquilino, S. A. (2005). Correspondence between maternal and paternal parenting styles in early childhood. Early Childhood Research Quarterly, 20(1), $1-12$. https://doi.org/10.1016/j.ecresq.2005. 01.007

Wu, P., Robinson, C. C., Yang, C., Hart, C.
H., Olsen, S. F., Porter, C. L., Jin, S., Wo, J., \& Wu, X. (2002). Similarities and differences in mothers' parenting of preschoolers in China and the United States. International Journal of Behavioral Development, 26(6), 481-491.

https://doi.org/10.1080/016502501430 00436

Yu, J. J., \& Gamble, W. C. (2008). Pathways of influence: Marital relationships and their association with parenting styles and sibling relationship quality. Journal of Child and Family Studies, 17(6), 757-778. https://doi.org/10.1007/s10826-0089188-z

Zhang, C., Cubbin, C., \& Ci, Q. (2019). Parenting stress and mother- child playful interaction: the role of emotional support. Journal of Family Studies, 25(2), 101-115. https://doi.org/10.1080/13229400.201 6.1200113 